\title{
PRODUCT MIX OF THE SPANISH BANKING FIRMS: DO COMPETITION CLUBS EXIST?*
}

\author{
Francisco Pérez and Emili Tortosa-Ausina ${ }^{\dagger}$
}

WP-EC 98-02

Correspondencia: Emili Tortosa-Ausina, Universitat Jaume I

Facultat de Ciències Jurídiques i Econòmiques, Departament d'Economia

Campus del Riu Sec

12071 Castelló de la Plana (Spain). Tel.: +34 964728 606, fax.: +34 964728 591, e-mail: tortosa@uji.es

Editor: Instituto Valenciano de Investigaciones Económicas, S.A.

First Edition: January 1998

ISBN: 84-482-1684-9 Depósito Legal: V-102-1998

IVIE working-papers offer in advance results of economic research under way in order to encourage a discussion process before sending them to scientific journals for their final publication.

\footnotetext{
${ }^{*}$ We are grateful to J. Maudos, J.M. Pastor and an anonymous referee for helpful comments. The usual disclaimers apply. Financial support from CICYT PB94-1523 is gratefully acknowledged.

${ }^{\dagger}$ F. Pérez (Universitat de València and IVIE); E. Tortosa-Ausina (Universitat Jaume I)
} 


\title{
PRODUCT MIX OF THE SPANISH BANKING FIRMS: DO COMPETITION CLUBS EXIST?
}

\author{
Francisco Pérez and Emili Tortosa-Ausina
}

\begin{abstract}
The expansion and intensification of banking competition, which has occurred in Spain during the last ten years, has allowed banks and savings banks to define their competitive strategies with more freedom. This paper analyzes the similarities and the differences in their product mix along with its time evolution. In particular, it attempts to identify the different kinds of firms and, on this ground, to analyze whether competition leads to the homogeneization (convergence) of product mixes between firms or groups of firms (clubs). The empirical success is higher when specialization clubs are considered, finding increased heterogeneity within the banking system as a whole but increased homogeneity within certain clusters of banks and savings banks.
\end{abstract}

Keywords: banking, convergence, product mix

\section{Resumen}

La expansión e intensificación de la competencia en el sector bancario ocurrida en España durante la última década ha permitido a bancos y cajas de ahorro definir sus estrategias competitivas con mayor libertad. Este artículo analiza las similitudes y diferencias en la especialización de las empresas bancarias y su evolución temporal. En particular, trata de identificar los distintos tipos de empresas y, a partir de ello, analizar si la competencia está condicionada o no por grupos (clubes) de competidores con especializaciones similares. Los resultados son superiores cuando se consideran clubes de especialización, obteniéndose heterogeneidad creciente para el conjunto del sistema bancario pero homogeneidad creciente dentro de ciertos grupos de bancos y cajas de ahorro.

Palabras clave: sector bancario, convergencia, especialización productiva 


\section{Introduction}

During the last decade, many European countries have witnessed a strong change in the conditions surrounding the banking industry. A new financial environment, deregulation, technological change and internationalization of the economies are some of the outstanding features of such transformations. Banking firms have been impelled to modify their competitive strategies in a wider context for products and markets. One of the more important components of such strategies has been the choice of a certain specialization in their production or product mix.

Bearing in mind that these are multiproduct firms, this paper attempts to identify the lines of specialization of banking firms in these circumstances, along with the evolution of such a specialization. The analysis is carried out through a database of Spanish banking firms; however, the interest of the exercise tries to capture also the usefulness of applying some of the frequently used techniques in the economic growth and inequality literature to the study of the specialization of multiproduct firms.

In order to analyze the banking product mix, a measurement of banking output is required. This question has often been involved in debate and controversy. ${ }^{1}$ According to our objective, it is necessary to use an output measure which allows us to identify product diversity. This is the reason underlying the use of the balance sheet items as output indicators, although this choice has well known shortcomings. ${ }^{2}$

The approach used in this paper to analyze the evolution of specialization in the banking industry has been considered in different studies. ${ }^{3}$ Pastor and Pérez 1998 for example, seek to analyze the differences in the product mix patterns between the aggregate of banks and savings banks considering each aggregate as the representative firm. In an approach similar to the one pursued in this paper, their study provides an overview of the changes faced by the banks and savings banks balance sheet structures over the last decade. They find that there is a tendency of both types of institutions to narrow or widen their product mixes

\footnotetext{
${ }^{1}$ See, for instance, Kolari and Zardkoohi 1987.

${ }^{2}$ However, some of such shortcomings, like the increasing importance of the off-balance sheet operations, have not been fully exploited in the literature on Spanish banking firms.

${ }^{3}$ See, for instance Freixas 1996, Gual and Hernández 1991 or Sánchez and Sastre 1995.
} 
throughout this period, during which the increase in competition has allowed them to choose less regulation-conditioned competitive strategies. The overall conclusion of their study is that, while there appears to be the convergence of product mix for certain balance sheet items, no clear pattern exists for the overwhelming majority of assets and liabilities items.

However, it is not possible from the aforementioned types of studies to achieve a conclusion as to whether the widening of markets and products has resulted in increased homogeneity (or diversity) within the banking sector or not from the exercise developed in the above mentioned study. Firstly, results tend to be ambiguous. Secondly, competitive strategies must be studied considering the individual firm, rather than any type of institution aggregate. For that reason, in our study possibilities to develop an analysis of the presented problem related to the banking firms are exploited.

As we try to study banking firms, both statistical and instrumental difficulties emerge. The former refers to the individual available data ${ }^{4}$ which does not offer the same level of detail as the aggregate data published by the Bank of Spain, which forces us to use slightly different product mix indicators. ${ }^{5}$ The latter is more substantial, as it deals with the way of building product mix indicators which synthesize the behaviour of multiple firms and multiple product lines. That will be the main goal of this paper.

\section{Basic product mix indicators}

The starting point lies on defining some basic product mix indicators from the chosen output measures. Let $X_{i j}$ be firm j's balance sheet's item $i$. When the items are asset items, they will be denoted by $A_{i j}$, and $L_{i j}$ when they are liability items. Let $X_{j}=A_{j}=L_{j}$ be the total value of such firm assets and liabilities. In the same way, let $X_{i}\left(A_{i}, L_{i}\right)$ be the aggregate value of item $i$ for a group of firms.

The output of a firm is defined by its assets and liabilities vector:

\footnotetext{
${ }^{4}$ These are published by the Spanish Banking Association (AEB) and the Spanish Confederation of Savings Banks (CECA).

${ }^{5}$ Nevertheless, as it is shown in Tortosa-Ausina 1997, when the Pastor and Pérez 1998 analysis for the aggregate are replicated, using AEB and CECA's individual data, the results do not differ.
} 


$$
X_{j}\left(A_{i j}, L_{i j}\right)
$$

The vectors of the firms as a whole make up a matrix:

$$
X\left(X_{j}\right)=X\left(A_{i j}, L_{i j}\right)
$$

This type of matrix, which includes the output of the firms in its rows, is available in every period. In the same way, we have two aggregate vectors: each firm's aggregate vector $\left(X_{j}\right)$ and each product aggregate vector $\left(X_{i}\right)$.

The basic group of product mix indicators is obtained through:

$$
x_{i j}=\frac{X_{i j}}{X_{j}}
$$

This matrix is made up of the elements defined in such a way. Its main advantage consists of every firm's row being comparable with the others, as the production scale elements have been corrected. Each column $i$ represents the intensity of the specialization of the different firms in product $i$.

Finally, the set of available data matrices $x_{i j}$ is conditioned only by the existing observations in the analyzed period $t$. For our purposes, we will employ 8 balance sheet items (columns) -4 assets items and 4 liabilities items-, 127 firms $^{6}$ (rows) and 11 years (matrices).

\footnotetext{
${ }^{6}$ Although our original sample consisted of a larger number of banks and savings banks, it was reduced for two reasons. Firstly, as the period of analysis has witnessed a high number of mergers and acquisitions, we considered the firms involved in such actions as the same firm since the beginning of the period. Secondly, we have dropped those firms having started out or ended up their activity during the considered period. Although this could seem an important loss of data, the analyzed banks and savings banks always represent around $90 \%$ of total assets.
} 


\section{Product mix measures}

Taking the $x_{i j}$ indicators as a starting point, it is possible to analyze the product mix from two different approaches:

1. From the homogeneity between firms.

2. From the time evolution.

\subsection{Homogeneity in specialization}

Let us consider now any of the column vectors in the matrix $x\left(x_{i j}\right)$. Each of the elements of the vector $i$ has a value which ranges from 0 to 1 and represents the intensity of the specialization in one of the different firms' balance sheets. A homogeneous or heterogeneous product mix measure in a certain period of any of the balance sheet items will be given by the density function dispersion measures made up of the available observations: either the variation coefficient $(\rho)$ or the standard deviation $(\sigma)$ (depending on whether we want to take into account the mean values of $x_{i j}$ for such an item or not).

The lowest values in the dispersion measures of the specialization coefficients show the banking firms being more homogeneous between them in the considered product line. As far as the variation coefficients are concerned, as they have been corrected by the mean, we are able to check out which items where the relative homogeneity between firms is higher, regardless of their importance in the balance sheet.

Table 2 shows the variation coefficients' values corresponding to the most important assets and liabilities items ${ }^{7}$ for each of the years of the sample. Table 1 shows in a decreasing order such coefficient values for the initial and final years and allows us to appreciate the highest relative inequality in "issued securities", "interbank deposits" and "other deposits";

\footnotetext{
${ }^{7}$ In the overwhelming majority of cases, they jointly represent around $90 \%$ of all assets.
} 
in the same way, comparing the starting and final data, it is possible to notice how the dispersion has fallen in some cases, but has increased in others, there being no a priori evident pattern towards homogeneity or diversity of the product mixes.

Table 1: Convergence in specialization (relative dispersion), banking firms (1985 vs 1995)

\begin{tabular}{lcll}
\hline \hline & 1985 & & 1995 \\
\hline Issued securities & 2,07 & Issued securities & 2,94 \\
Interbank deposits & 1,41 & Interbank deposits & 1,16 \\
Interbank loans & 0,84 & Other deposits & 1,07 \\
Other deposits & 0,72 & Fixed-income securities & 0,69 \\
Savings deposits & 0,53 & Interbank loans & 0,69 \\
Cash and Bank of Spain & 0,49 & Cash and Bank of Spain & 0,58 \\
Fixed-income securities & 0,39 & Savings deposits & 0,47 \\
Credit to firms and households & 0,36 & Credit to firms and households & 0,46 \\
\hline \hline
\end{tabular}

\subsection{Evolution of specialization: do tendencies exist?}

Table 2 leads us in a natural way to wonder whether a steady tendency towards the homogeneity of product mixes exists or not. In order to identify such a tendency, we represent graphically the time evolution of a certain $x_{i j}$ item variation coefficients' values. ${ }^{8}$ Its decreasing evolution points out firms converging in the intensity of their specialization in the item being analyzed. We will talk about divergence in the opposite case.

Figure 1 shows the results for the four analyzed assets items, while figure 2 does the same for the liability side. It is possible to notice a clear tendency towards convergence in "interbank loans" but, on the other hand, "fixed-income securities", "other deposits", "issued securities" and even (although to a lesser extent) "credit to firms and households" show a tendency towards diversity.

\footnotetext{
${ }^{8}$ Such a representation has become usual in the empirical literature on economic growth in the nineties, from the Barro and Sala-i-Martin 1992 study, where the concept of $\sigma$-convergence is defined.
} 


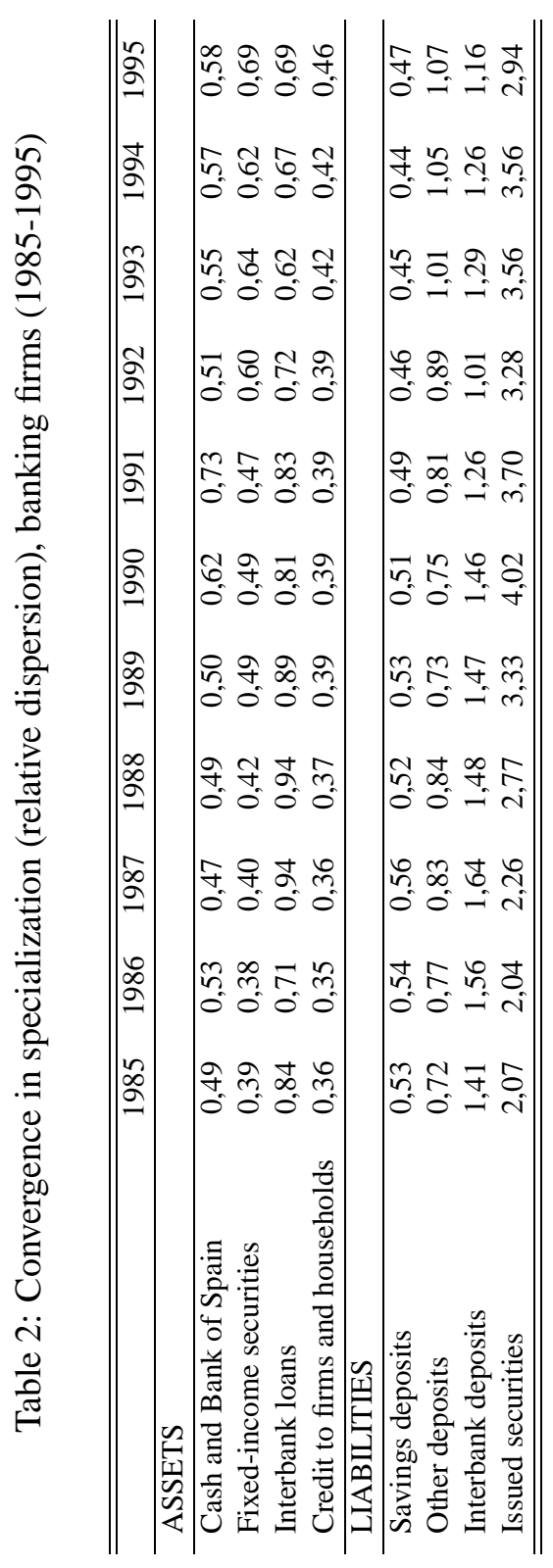



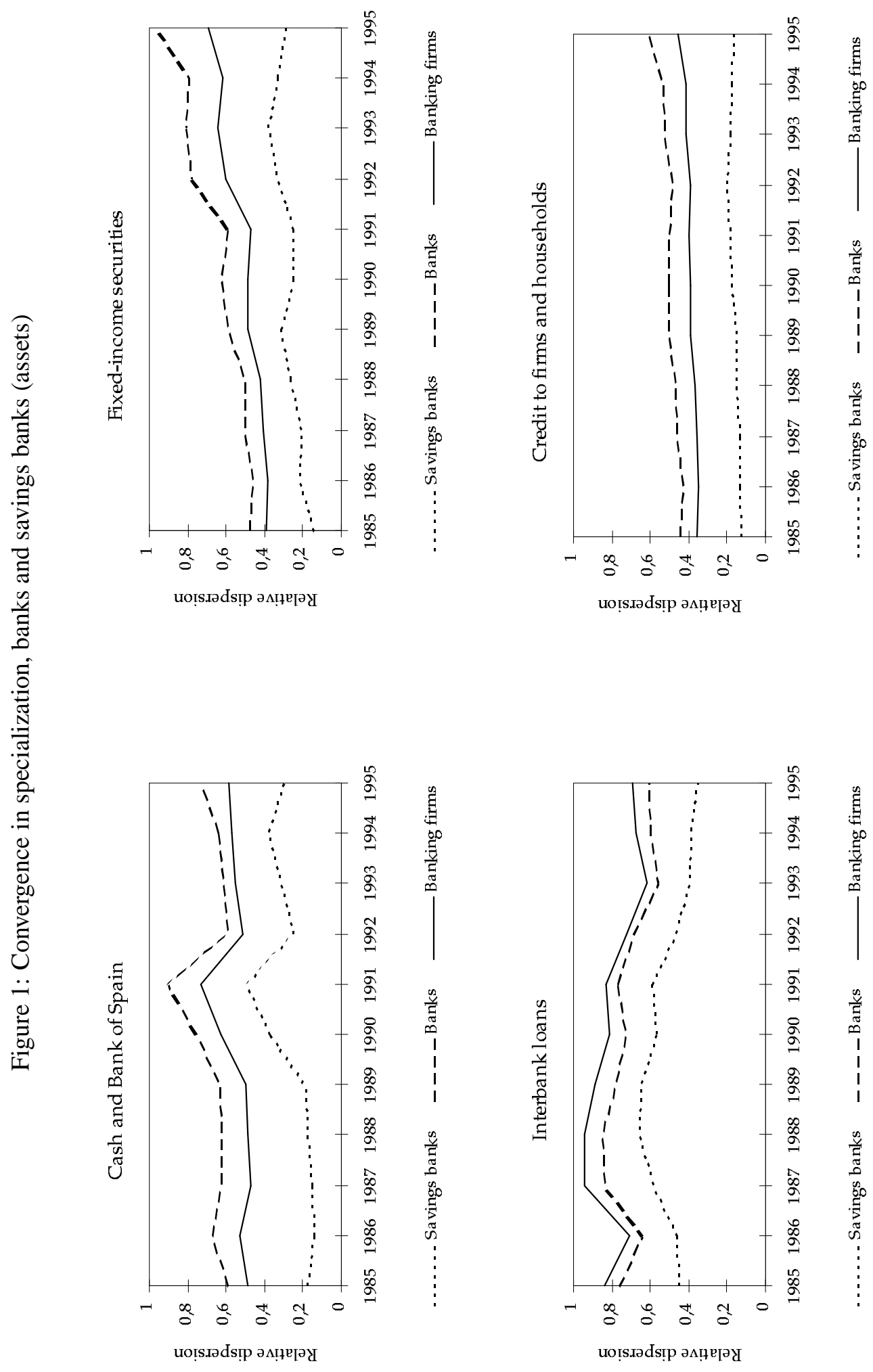

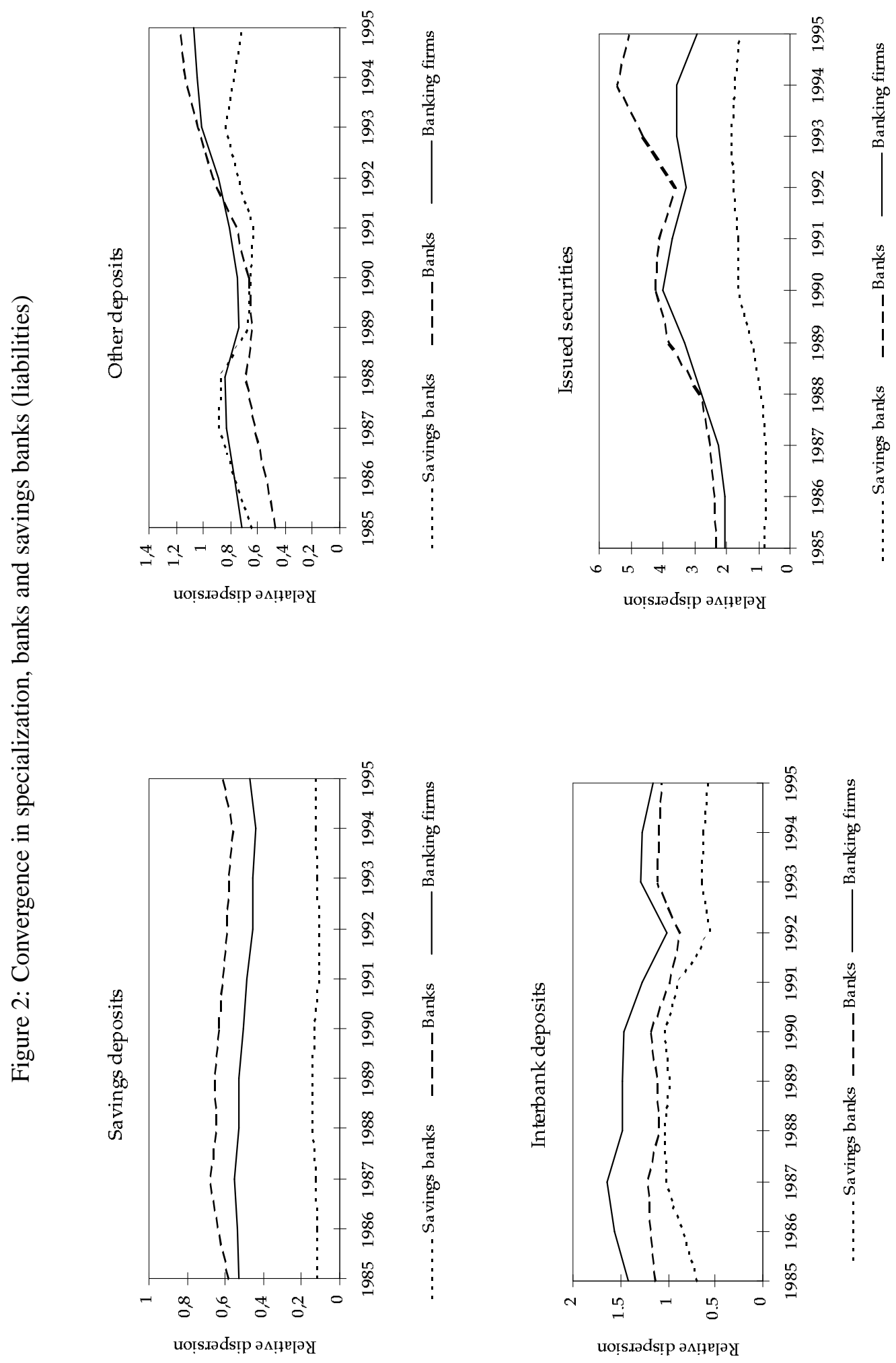
Another way to consider the tendency in the specializations approach deals with analyzing if the intensity of the specialization at the initial moment influences the specialization rate of change throughout the period being analyzed. Thus, if the fact of a firm being more oriented towards a certain specialization leads it to experience smaller intensifications of such a specialization in the future and, on the other hand, if the initially less specialized firms grow faster in that way, we will notice an inverse relationship between the initial level $x_{i j, 0}$ and the rate of variation of such a measure. ${ }^{9}$ This behaviour leads to closer final $x_{i j}$ values, so we will test in another way how product mixes converge.

In order to quantify if $\beta$-convergence exists, we must estimate for all the items the equation:

$$
\frac{1}{T} \log \frac{x_{i j, t}}{x_{i j, t-T}}=a-\beta \log \left(x_{i j, t-T}\right)+u_{i j, t-T}
$$

where $T$ represents the length of the analyzed period and $u_{i j, t-T}$ the error term.

Table 3 shows the estimates for equation (4) using least squares estimation for all of the contemplated balance sheet items of the considered Spanish banking enterprises. The results shown in the table allow us to assess the general sign of the tendency throughout the period. However, they do not allow us to notice the shocks which have taken place at any point in time. The value of the estimated $\beta$ shows us the rate at which banking firms converge or diverge in a certain specialization.

Excluding the "issued securities" case, we notice convergence in all product lines, although the fitness of the regression $\left(R^{2}\right)$ is somewhat poor in the "fixed-income securities" and "credit to firms and households" items. The $\beta$ values, which show the rate at which firms are getting closer in their specialization, suggest us that the required time for the $x_{i j}$ of the different firms relating to a certain column to be equalized is rather long. The rate is high in the case of "savings deposits" and "other deposits", as well as "cash and Bank of Spain" and the interbank operations (both loans and deposits); in the remaining items,

\footnotetext{
${ }^{9}$ Again, this approach to convergence was proposed by Barro and Sala-i-Martin 1992 and has been widely used in the study of convergence in per capita incomes. It is known as $\beta$-convergence.
} 
Table 3: Convergence in specialization, banking firms (1985-1995)

\begin{tabular}{|c|c|c|}
\hline & & $\begin{array}{c}\text { Banks and } \\
\text { savings banks }\end{array}$ \\
\hline \multirow{3}{*}{ Cash and Bank of Spain } & $\beta$ & 0.0575 \\
\hline & (t-Student) & $(9.8222)$ \\
\hline & $R^{2}$ & 0.4396 \\
\hline \multirow{3}{*}{ Fixed-income securities } & $\beta$ & 0.0341 \\
\hline & (t-Student) & $(2.87)$ \\
\hline & $R^{2}$ & 0.0647 \\
\hline \multirow{3}{*}{ Interbank loans } & $\beta$ & 0.055 \\
\hline & (t-Student) & $(7.5465)$ \\
\hline & $R^{2}$ & 0.3147 \\
\hline \multirow{3}{*}{ Credit to firms and households } & $\beta$ & 0.0315 \\
\hline & (t-Student) & $(2.3081)$ \\
\hline & $R^{2}$ & 0.0412 \\
\hline \multirow{3}{*}{ Savings deposits } & $\beta$ & 0.0652 \\
\hline & (t-Student) & $(11.7823)$ \\
\hline & $R^{2}$ & 0.5405 \\
\hline \multirow{3}{*}{ Other deposits } & $\beta$ & 0.0727 \\
\hline & (t-Student) & $(6.9046)$ \\
\hline & $R^{2}$ & 0.2777 \\
\hline \multirow{3}{*}{ Interbank deposits } & $\beta$ & 0.0634 \\
\hline & (t-Student) & $(10.0319)$ \\
\hline & $R^{2}$ & 0.4711 \\
\hline \multirow{3}{*}{ Issued securities } & $\beta$ & 0.0169 \\
\hline & (t-Student) & $(0.8887)$ \\
\hline & $R^{2}$ & 0.0248 \\
\hline
\end{tabular}

$\beta$ values closer to zero suggest slower convergence. 
convergence takes place at a much slower rate.

The resulting conclusion of this analysis lies in a certain approach in the specializations of Spanish banking firms when $\beta$-convergence is considered, although the speed differs substantially depending on the analyzed item. These results are not confirmed when using $\sigma$-convergence: in this case neither generalized nor clear patterns emerge. However, if we interpret these results as a lack of relationship in the banks' selected product mixes, the prediction would not be consistent with the general idea of Spanish banks being increasingly sensitive to the others firms' product mixes. Thus, it is possible that banks and savings banks concerns about other firms specializations are focused only on their most immediate rivals. In such a case, in order to appreciate convergence it would be necessary to observe in a different way the conduct of Spanish banking firms, trying to identify the groups of banks and savings banks which compete against each others.

\section{Do competition clubs exist?}

One of the possible choices is that, indeed, as Kolari and Zardkoohi 1987 pointed out, banking firms should not be treated as one homogeneous group, as they use "to cluster around specific market niches that are distinct from other markets". Thus, it would be more interesting to study the evolution of the specialization between groups of competitors instead of all banks. The regarded hypotheses to identify rival groups are multiple, but we will consider the following:

Type of institution: in this case, the hypothesis lies in the difference between banks and savings banks being significant for specialization due to their historical trajectory, as they currently face the same regulatory environment.

Size: we consider here large firms being rivals and imitating each other in their product mix. The same occurs with medium and small firms.

The own product mix: in this case, the posed idea lies on firms' chosen specializations being the relevant issue to identify competitors and, therefore, to analyze the evolution 
of specialization. ${ }^{10}$

The analysis in each of the different alternatives is focused as follows. Firstly, depending on the selected criterion, groups on which the evolution of specialization is going to be analyzed must be identified. Secondly, it is necessary to check out if such a grouping influences firms' convergence in specialization, both on its existence and its rate.

As far as the construction of the analyzed groups is concerned, and with reference to the first hypothesis we have made, the institutional difference between banks and savings banks leads to an automatic clustering of firms. The size hypothesis forces us to decide on the selected steps, finally choosing four categories. ${ }^{11}$ Finally, the chosen criterion to cluster firms by their product mix consists of identifying the specialization patterns from the $x_{i j}$ indicators and using the cluster analysis multivariate statistical technique. This analysis allows us to identify, through the application of a similarity or distance criterium to the different $x_{i j}$, how close firms specializations are. Once the distances have been computed, the following step deals with including in the same group (or cluster of firms) which have an output mix similar to that of all other banks and savings banks in their group but unlike those firms in all other groups. ${ }^{12}$ The Ward's method, which minimizes the intra groups variance, has been chosen to form the analyzed clusters. ${ }^{13}$

From these criteria, and applying them to 1995 data, nine groups have been selected, labelled with the table 4 names, with the institutional nature (bank or savings bank) and

\footnotetext{
${ }^{10}$ This approach has the shortcoming, pointed out by Dowrick and Nguyen 1989, of being an a posteriori study of convergence. Thus, it could be argued that there exists an ex post bias in favour of convergence as firms in each group show a similar product mix at the end of the analyzed period.

${ }^{11}$ Large banks and large savings banks ( 8 firms, which represent $49 \%$ of banking system's total assets in 1995), medium banks ( 7 firms and $7 \%$ of total assets), medium savings banks (11 firms and 12\%) and the remaining entities (101 firms, which represent $21 \%$ ).

${ }^{12}$ This approach has been used in other studies on banking product mix. See Freixas 1996, Gual and Hernández 1991, Kolari and Zardkoohi 1987, Korobow and Stuhr 1989 or Sánchez and Sastre 1995.

${ }^{13}$ For a detailed exposition of the adopted method in the cluster formation and in the selection of the considered ones, see Tortosa-Ausina 1997. The chosen similarity measure to compute the distances has been the squared Euclidean distance, defined as:

$$
d_{i j}=\sum_{k=1}^{p}\left(x_{i k}-x_{j k}\right)^{2}
$$

where $x_{i k}$ and $x_{j k}$ are the observations values $i$ and $j$ for the $x$ variable, and $p$ is the number of variables (ratios) which characterize each observation (enterprise).
} 
each firm and group shares of total banking sector assets indicated there.

Once banks and savings banks have been grouped according to the three described hypotheses, the $\sigma$ and $\beta$ convergence analysis has been replicated for each of the resultant banks' clusters: two in the first hypothesis, four in the second and nine in the third. As far as $\sigma$-convergence is concerned, it is difficult to define general behaviour guidelines because of the heterogeneity in the results, as we got before. ${ }^{14}$ On the other hand, the $\beta$-convergence analysis does help us in assessing if the specialization throughout the 1985-1995 period is influenced (conditioned) in its significance or rate by the selected clusters of banks and savings banks. The expression of the $\beta$-convergence equation to be estimated is now:

$$
\frac{1}{T} \log \frac{x_{i j, t}}{x_{i j, t-T}}=a-\beta \log \left(x_{i j, t-T}\right)+\phi z_{i j}+u_{i j, t-T}
$$

where $z_{i j}$ is a vector of dummy variables which takes value 1 or 0 depending on the firm belonging to a certain cluster or not.

The results of the estimation with the first clustering (banks and savings banks) show a certain increase in the rate of convergence of some balance sheet items, specially between savings banks, although changes are not important (see table 5, column 1). The second series of estimations, related to the clustering by size, show dimension as a little conditioning factor when analyzing convergence in specialization, except for certain items (see table 5, column 2) for group 2 (medium banks). ${ }^{15}$ Finally, the third of the clustering hypothesis does noticeably affect the results (see table 5, column 3), leading to an important increase in the fitness of the regression $\left(R^{2}\right)$ and the $\beta$ values which represent the rate of convergence.

The way to interpret such results is the following: if banking firms are clustered by their current product mix similarity, and their last decade trajectory is analyzed, we verify that, caeteris paribus, each of the clusters will have converged to a very similar product mix in few years. In other words, if the current strategies in what specialization concerns are held,

\footnotetext{
${ }^{14}$ See Tortosa-Ausina 1997.

${ }^{15}$ Again, further details of this analysis are thoroughly presented in Tortosa-Ausina 1997.
} 


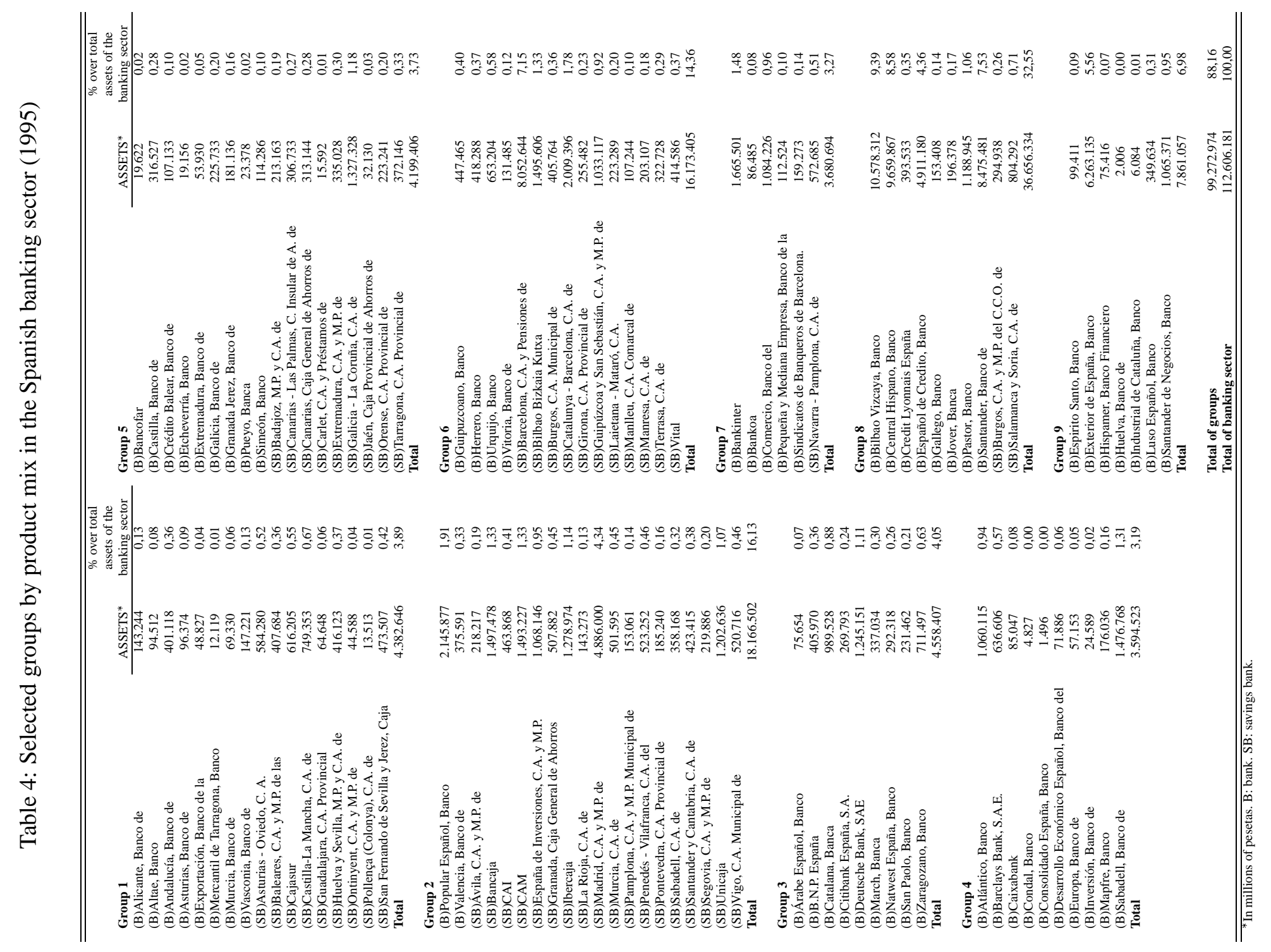


Table 5: Convergence in specialization, banking firms (1985-1995)

\begin{tabular}{|c|c|c|c|c|}
\hline & & $\begin{array}{c}\text { Type of } \\
\text { institution }\end{array}$ & Size & $\begin{array}{c}\text { Product } \\
\text { mix }^{\diamond}\end{array}$ \\
\hline \multirow{3}{*}{ Cash and Bank of Spain } & $\beta$ & 0.0662 & 0.0578 & 0.0727 \\
\hline & (t-Student) & (10.9484) & $(9.6514)$ & $(12.951)$ \\
\hline & $R^{2}$ & 0.4964 & 0.4433 & 0.6831 \\
\hline \multirow{3}{*}{ Fixed-income securities } & $\beta$ & 0.0535 & 0.0068 & 0.0958 \\
\hline & (t-Student) & $(4.3801)$ & $(0.3772)$ & $(13.6449)$ \\
\hline & $R^{2}$ & 0.1758 & 0.0675 & 0.6974 \\
\hline \multirow{3}{*}{ Interbank loans } & $\beta$ & 0.0659 & 0.056 & 0.0872 \\
\hline & (t-Student) & $(8.4693)$ & (7.608) & $(16.4191)$ \\
\hline & $R^{2}$ & 0.369 & 0.3256 & 0.7594 \\
\hline \multirow{3}{*}{ Credit to firms and households } & $\beta$ & 0.037 & 0.0393 & 0.0956 \\
\hline & (t-Student) & $(2.7897)$ & $(2.0132)$ & $(9.3203)$ \\
\hline & $R^{2}$ & 0.1161 & 0.0398 & 0.6356 \\
\hline \multirow{3}{*}{ Savings deposits } & $\beta$ & 0.0722 & 0.0657 & 0.075 \\
\hline & (t-Student) & (11.6407) & $(11.5175)$ & $(29.1481)$ \\
\hline & $R^{2}$ & 0.5609 & 0.542 & 0.9065 \\
\hline \multirow{3}{*}{ Other deposits } & $\beta$ & 0.0499 & 0.0731 & 0.0974 \\
\hline & (t-Student) & $(3.9002)$ & $(6.8144)$ & $(13.3681)$ \\
\hline & $R^{2}$ & 0.3258 & 0.3234 & 0.7632 \\
\hline \multirow{3}{*}{ Interbank deposits } & $\beta$ & 0.0721 & 0.0684 & 0.0814 \\
\hline & (t-Student) & $(10.047)$ & (10.5029) & $(15.6455)$ \\
\hline & $R^{2}$ & 0.4968 & 0.5015 & 0.763 \\
\hline \multirow{3}{*}{ Issued securities } & $\beta$ & 0.0174 & 0.0071 & 0.0194 \\
\hline & (t-Student) & $(0.9675)$ & $(0.285)$ & $(0.0545)$ \\
\hline & $R^{2}$ & 0.1606 & 0.0262 & 0.7169 \\
\hline
\end{tabular}


there will be groups of firms with almost homogeneous product bundles, depending on the level of detail that the available information permits.

\section{Where is the banking sector diversity?}

According to what we have seen, when all banking firms are considered, the different firms' product mixes do not show a clear pattern either towards homogeneity or towards diversity. If an aggregate indicator of the $\sigma$-convergence indicators is designed, as a weighted mean of such indicators, a slight increase in heterogeneity is appreciated. This statement is justified by considering the weighted variance of the assets or liabilities specialization indicators, or the whole balance sheet, computed in the following way:

$$
\sigma_{\omega}^{2}=\sum_{i=1}^{n} \frac{X_{i}}{\sum_{i=1}^{p} X_{i}} \sigma_{i}^{2}
$$

where $\sigma_{i}^{2}, i=1 \ldots n$, represents the sample variance of each of the variables considered in the balance sheet analysis of the banking firms, $n=4,8$ (depending on whether we analyze a single balance sheet side or the total balance sheet) and $p=4$.

Figure 3 shows an increase of the dispersion in the assets side of the balance sheet, although there are not clear tendencies in what the liabilities side concerns. In the same way, it shows higher dispersion when the whole balance sheet is contemplated, along with an increasing heterogeneity.

Despite of all this, if the observed tendency to homogeneity in the conduct of the Spanish banking firms when the convergence between the members of a competitors' club which face the same specialization patterns is considered, we might wonder whether it is possible or not that a simultaneous increase in the diversity between groups together with a reduction of such diversity within groups is taking place.

In order to answer the above question, we might initially contemplate the same aggre- 
Figure 3: Convergence in specialization, total balance sheet (banks and savings banks)

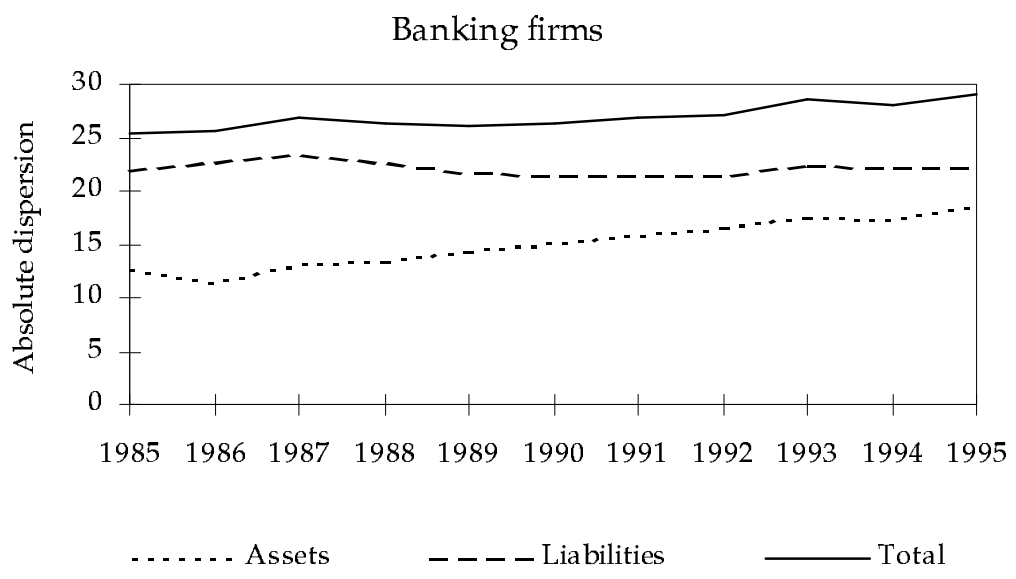

gate indicator for the product mix evolution, but computing it for each of the nine identified groups. The results are, according to figure 4, very different from the presented above. Firstly, we observe that convergence in the whole balance sheet exists for the overwhelming majority of groups, specially during the nineties. Secondly, a clear tendency towards convergence in the liabilities specialization in eight of the nine groups is achieved, whereas no steady tendency is observed for the assets.

Thus, results vary depending on the contemplated grouping of banking firms. According to this, it is interesting to analyze their joint meaning, along with their compatibility. With this purpose, we might employ a widely used instrument in the inequality studies: the Theil index. Such an index has the appealing feature of allowing a decomposition of the total inequality in terms of the observed inequality between different data groupings.

Our attempt is to differentiate the contribution to the total inequality evolution of the differences between groups and within groups. The Theil index is computed according to the expression: 

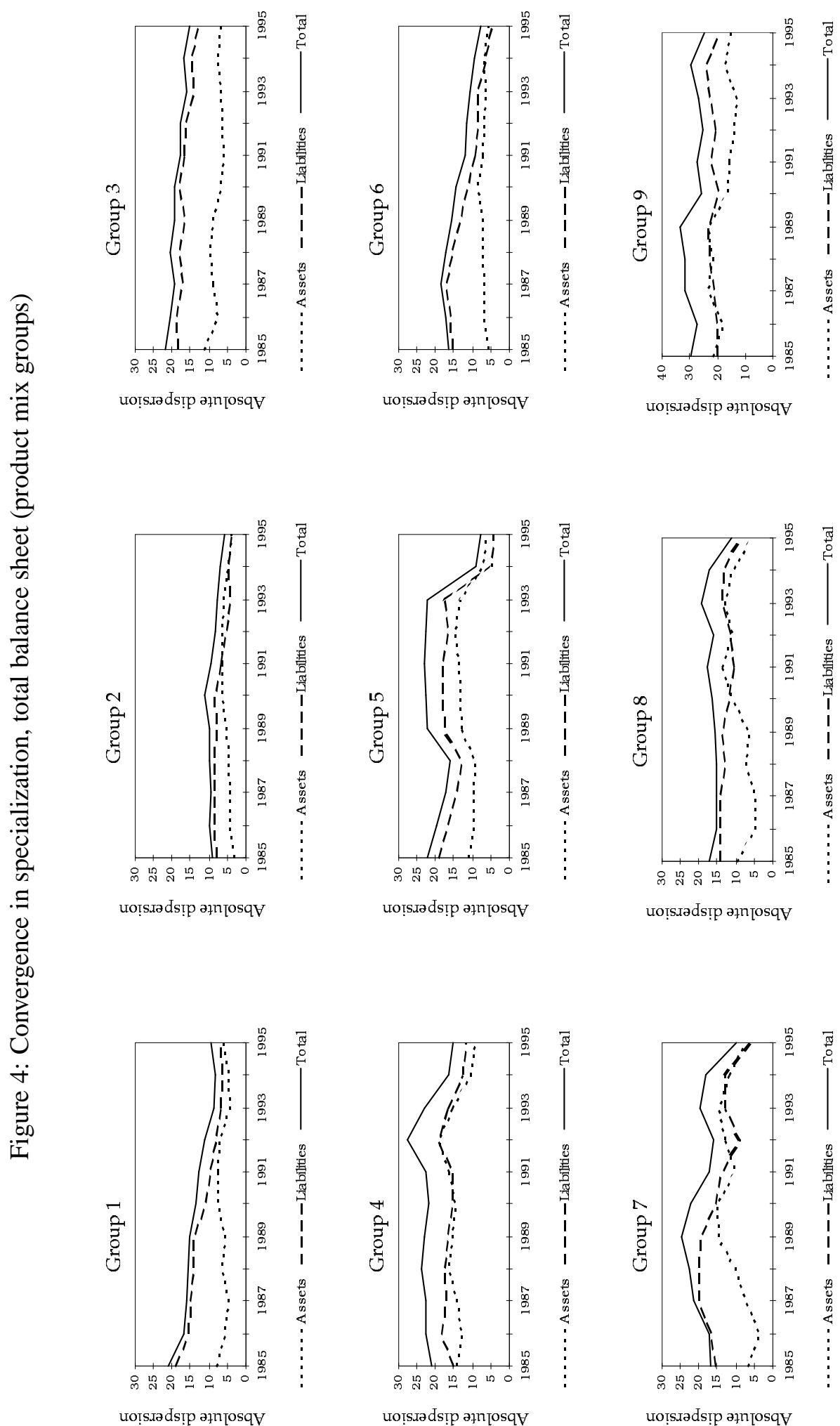


$$
T I=\sum_{i=1}^{I} x_{i} \log \frac{x_{i}}{y_{i}}+\sum_{i=1}^{I} x_{i} \sum_{j=1}^{J} \frac{x_{i j}}{x_{i}} \log \frac{\frac{x_{i j}}{x_{i}}}{\frac{y_{i j}}{y_{i}}}
$$

where

$T I:$ total inequality

$i=1 \ldots I$ : cluster's subscript

$I$ : number of clusters being considered

$j=1 \ldots J$ : firm's subscript

$J$ : number of firms in each cluster

$x_{i}=\frac{\text { total item amount of the } i^{\text {th }} \text { cluster }}{\text { total item amount of all } n \text { clusters }}$

$y_{j}=\frac{\text { total assets of the } i^{\text {th }} \text { cluster }}{\text { total assets of all } n \text { clusters }}$

$x_{i j}=\frac{\text { total item amount of the } j^{\text {th }} \text { firm affiliated to cluster } i}{\text { total item amount of } i^{\text {th }} \text { cluster }}$

$y_{i j}=\frac{\text { total assets of the } j^{\text {th }} \text { firm }}{\text { total assets of all } n \text { clusters }}$

The first term on the right represents the contribution to the total inequality (for a certain item) of the between groups inequality. The second term is the weighted sum of the inequality (concerning to the analyzed item) between the firms within each of the clusters. Thus, we are considering separately the inequality between cluster and within cluster for the item being analyzed.

The results of the Theil index computations applied to our data show that the index behaviour presents an increasing inequality for the total and between groups, but decreasing inequality within groups (see figures 5 and 6 ). In the same way, the total existing inequality in each period is explained in an increasing percentage by the inequality between groups, which shows that the degree of the product line diversity is progressively being configured as a result of the different product bundles offered by the different clubs of firms (see figures 7 and 8).

This joint assessment might be transferred to each of the contemplated product lines (the eight balance sheet items). For all of them, the intra groups inequality is decreasing 

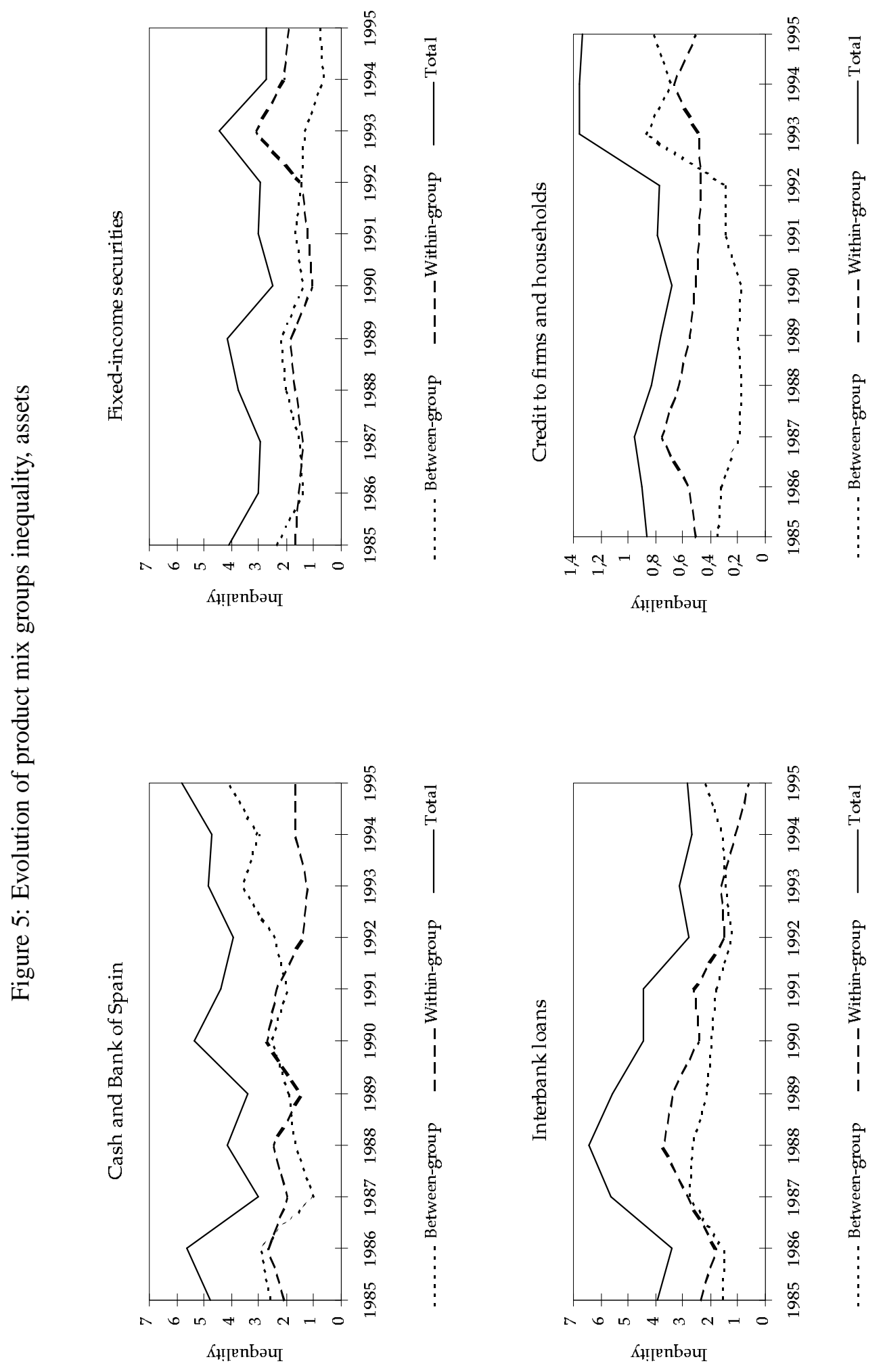

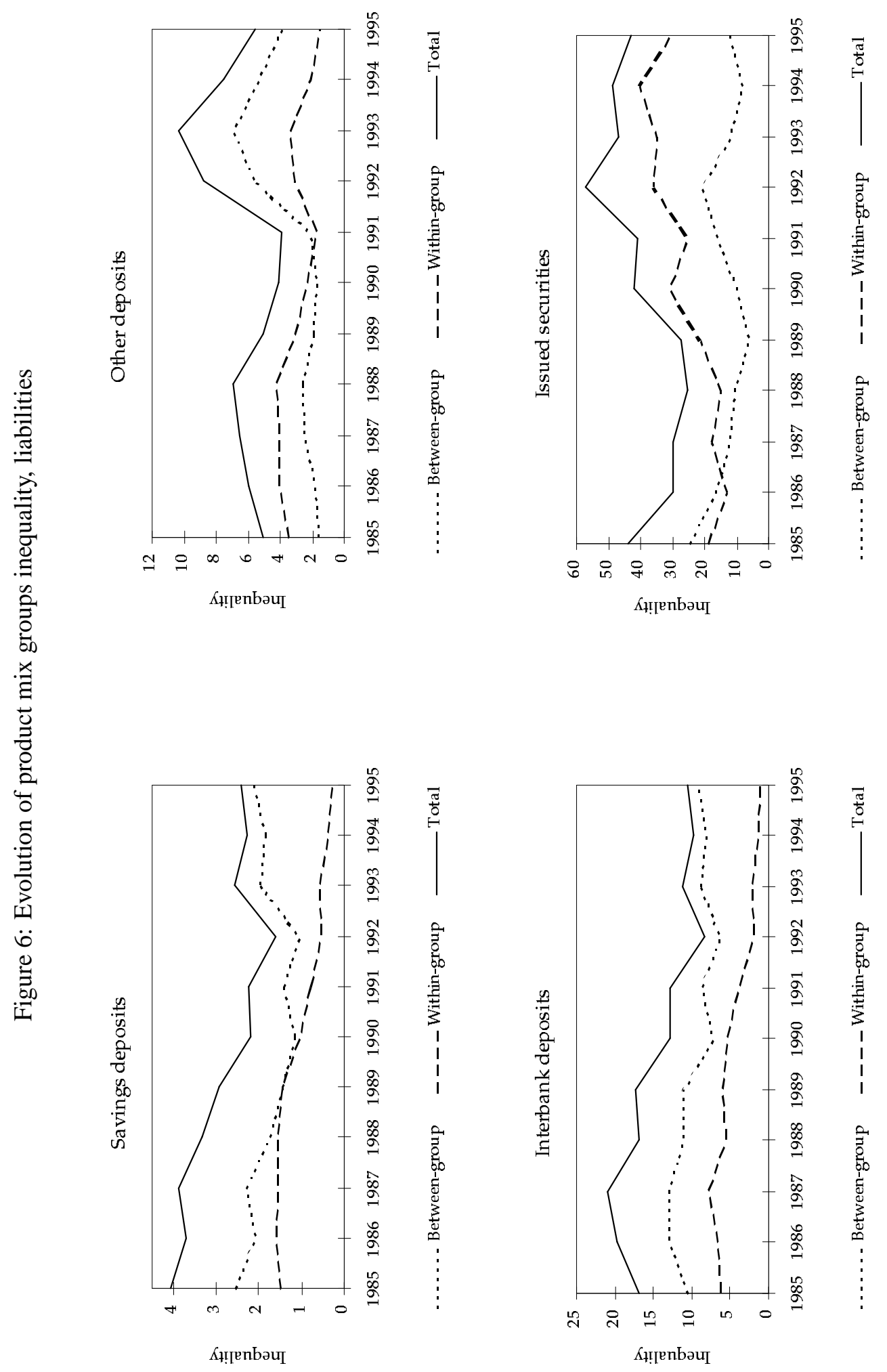


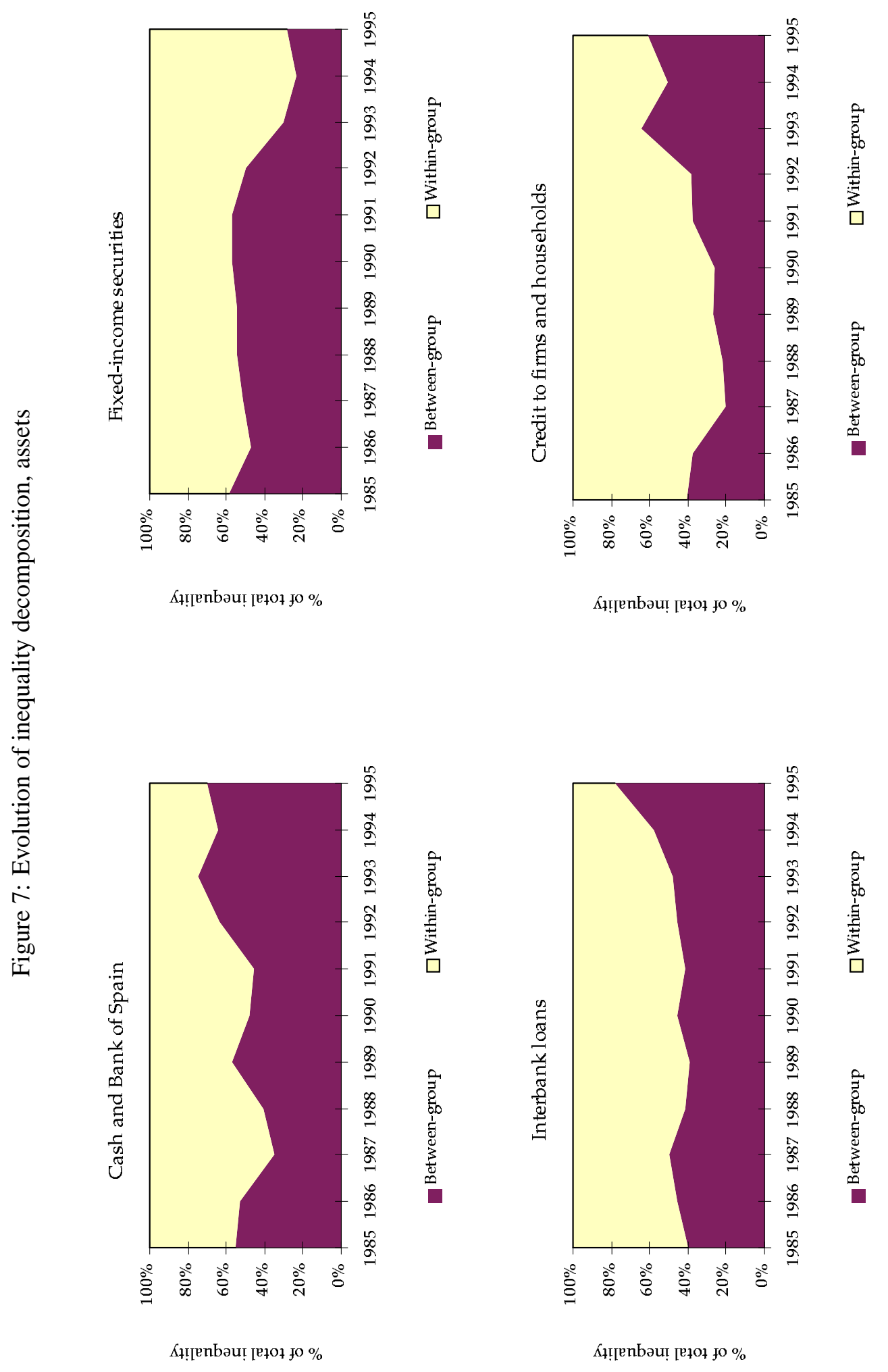




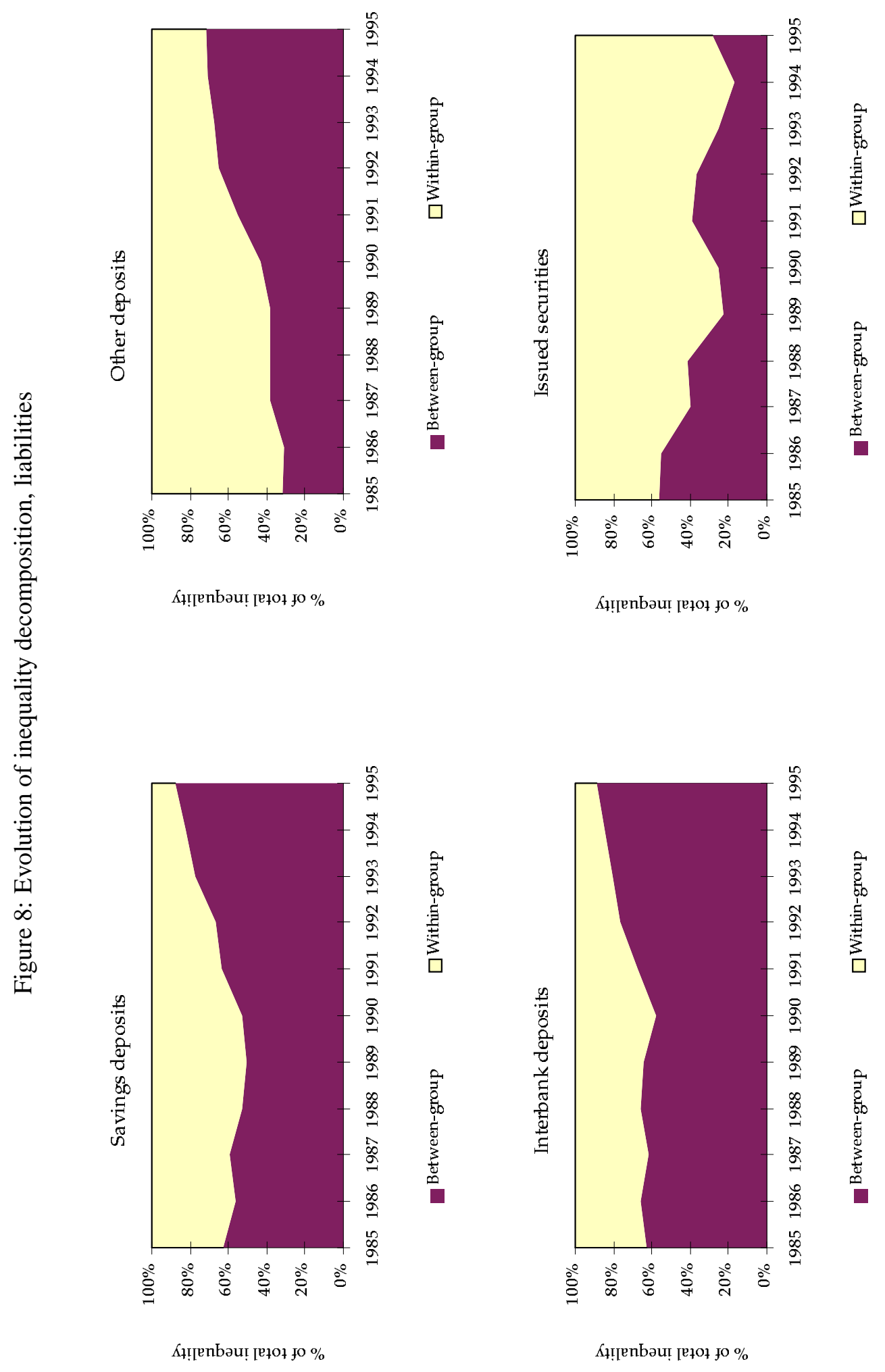


and hardly represents a $20 \%$ of the total (see figures 5, 6, 7 and 8). The two exceptions are "issued securities" and "fixed-income securities", both of them related to the securitization and, probably, to off-balance sheet activities.

\section{Concluding comments}

The developed analysis in the above sections has allowed us to approach the analysis of the product mix evolution of the banking firms, and its tendency towards convergence or divergence. The instruments used help us in detecting some features of such evolution; to be exact, we have found that the higher freedom of banking firms in a less regulated and more competitive context seems to produce a range of specializations or combinations of the balance sheet items which makes banks more heterogeneous in their product mix. However, it can also be appreciated that a special kind of similar firms in their specializations is being defined, and within each group we notice a fast and clear tendency towards more and more homogeneous product mixes.

As a consequence of the presented results, the heterogeneity of the specializations is increasingly higher between the different clusters but lower within them. If this tendency is confirmed, we might reasonably hope more similar product conditions within these clubs of firms competing against each others with similar product mixes. In this case, the developed analysis on specialization should be regarded as a starting point for the study of the differences in unit costs and scope economies. To be exact, it should help us in analyzing if the different groups, as they produce different product ranges, employ significatively distinct cost functions and other production characteristics. 


\section{References}

BARRo, R.J. AND S ALA-I-MARTIN, X. (1992): “Convergence," Journal of Political Economy, 100, 2, 223-251.

Dowrick, S. AND NGuYen, D.T. (1989): “OECD Comparative Economic Growth 195085: Catch-Up and Convergence,” American Economic Review, 78, 5, 1010-1030.

FreIXAS, X. (1996): Los límites de la competencia en la banca española, Fundación BBV, Bilbao.

GuAL, J. AND HERnÁNDEZ, A. (1991): “Costes operativos, tamaño y especialización en las cajas de ahorro españolas," Investigaciones Económicas, 15, 3, 701-726.

Kolari, J. And Zardkoohi, A. (1987): Bank Costs, Structure and Performance, Lexington, Massachussets/Toronto.

Korobow, L. And Stuhr, D.P. (1989): “A New Look at U.S. Banking Strategy and Structure in the 1980s,” Research Paper 8917, Federal Reserve Bank of New York.

PASTOR, J.M. AND PÉREZ, F. (1998): “Especialización y competitividad de las cajas de ahorros (1984-1996)," Papeles de Economía Española, 74-75, 168-189.

SÁnchez, J.M. AND SASTRE, M.T. (1995): “¿Es el tamaño un factor explicativo de las diferencias entre entidades bancarias?" Documento de trabajo 9512, Banco de España, Servicio de estudios.

Tortosa-Ausina, E. (1997): "Especialización productiva y clubs de competencia en las empresas bancarias españolas: evidencia empírica (1985-1995)," Mimeo. 